Bangl. J. Vet. Med. (2016). 14 (2): 183-190

ISSN: 1729-7893 (Print), 2308-0922 (Online)

\title{
PREVALENCE OF REPEAT BREEDING AND ITS EFFECTIVE TREATMENT IN COWS AT SELECTED AREAS OF BANGLADESH
}

\author{
K. M. Asaduzzaman, M. M. U. Bhuiyan*, M. M. Rahman and J. Bhattacharjee
}

Department of Surgery and Obstetrics, Faculty of Veterinary Science, Bangladesh Agricultural University, Mymensingh 2202, Bangladesh

\begin{abstract}
ASTRACT
The objectives of the study were to determine the prevalence of repeat breeding and its associated risk factors in cows at selected areas of Bangladesh followed by determination of an effective treatment regime for those cows. Data were collected by interviewing the owner of the cows from 172 farms having 1524 breedable cows located at one Upazila of Mymensingh, Chittagong, Khulna, Satkhira, Bogra and Dhaka districts. A total of 122 repeat breeding cows were treated and randomly distributed into 5 experimental groups for different treatment regimes. The treatment regimes were (i) single AI with injection of $500 \mu \mathrm{g}$ of gonadorelin, (ii) intra uterine infusion of 4.0 million i.u. penicillin daily for 3 days followed by single AI at next estrus, (iii) same time AI with double doses of semen, (iv) two times AI at 8 hours interval and (v) single AI without any intervention (used as control group). Information was collected for all treated cows for returning to estrus at 20-22 days postAI. If the cow did not return to estrus at 20-22 days post-AI, the cows were examined for pregnancy by per rectal palpation of genital tract at 60-90 days post-AI. The pregnancy of the treated cows was used as the indicator of success of each treatment regime. The overall prevalence of repeat breeding in cows was $11.5 \%$. The breed of cows, herd BCS and farm size influenced the prevalence of repeat breeding in cows. The age, parity, BCS and milk yield influenced the occurrence of repeat breeding in individual cows. The significantly higher proportion of cows recovered when AI was done using double doses of semen (52.8\%) or single AI was done with GnRH administration (51.9\%) than no intervention control (30.4\%). In conclusion, repeat breeding cows may be inseminated with double doses of semen or with single AI with GnRH administration for improvement of conception.
\end{abstract}

Key words: Cows, prevalence, repeat breeding, treatment

\section{INTRODUCTION}

Bangladesh is an agriculture based country and maximum peoples live at rural areas under poverty level. In our country, dairy can be an important sector for rural development and poverty alleviation. Reproductive efficiency is essential for profitable dairy farms (Nebel and Jobst, 1998). Economy of dairy farming largely depends on good conception rates after insemination. Poor conception rate and delayed conception have been identified as major constraints of profitable dairy farming in Bangladesh (Alam and Gosh, 1988; Shamsuddin et al., 2001). Reproductive disorders have also been responsible for remarkable economic loss to the farmers and dairy industry in Bangladesh (Mia and Islam, 1967). Among reproductive disorders, repeat breeding syndrome may play a vital role in delayed conception in Bangladesh resulting in increased inter calving interval. The economic loss is due to delay in conception, that maintain the animals in a non-productive state for long period, increases number of services per conception, prolonged inter-calving intervals and increased culling rates (Bartlett et al., 1986; Lafi and Kaneene, 1992). A repeat breeder is generally defined as any cow that has not conceived after three or more services, has normal estrus cycle, is free from palpable abnormalities, shows no abnormal vaginal discharges, has calved at least once before and is less than ten years old. Repeat breeding has also been defined as failure to conceive from 3 or more regularly spaced services in the absence of detectable abnormalities (Zemjanis, 1980).

Usually about 9-12\% cows are expected to be repeat breeder in a herd with normal fertility and with 50-55\% conception rates (Reneau and Conlin, 1984). The occurrence of repeat breeding in Swedish dairy cattle was $10.1 \%$ and the cause was multifactorial involving a number of extrinsic factors as well as intrinsic factors associated with individual animals (Gustafsson and Emanuelson, 2002). Fertilization failure and early embryonic

*Corresponding e-mail address: mmubhuiyan@gmail.com 


\section{K. M. Asaduzzaman and others}

death are the major causes of repeat breeding those are influenced by uterine infection, genetics, ovulatory failure, error in estrus detection, improper timing of service. When artificial insemination is used, some of the animals might have been inseminated at wrong time (Shamsuddin et al., 2001) leading to increased proportion of repeat breeding in Bangladesh. Moreover, Jainudeen and Hafez (2000) reported higher incidence of repeat breeding in dairy herds using artificial insemination than that used natural services. Further, many risk factors such as breed of cows, herd body condition score (BCS), number of breedable cows in each farm may influence the occurrence of repeat breeding in population. Nevertheless, age, parity, BCS and milk yield of cows may affect the occurrence of repeat breeding in individual cows.

Usually repeat breeder cows are diagnosed and treated by the veterinarians on the basis of history of the previous services and clinical examination of the cows. However, accurate treatment for repeat breeder cows has not been possible in most cases and the success of such treatment is not evaluated. Induction of ovulation by administration of gonadotrophin releasing hormone $(\mathrm{GnRH})$ is commonly practiced in cattle to treat repeat breeders (Taponen et al., 1999). GnRH has been used at the time of AI in repeat breeding cows for improvement of conception in Bangladesh (Hossain, 2002). It is likely that two times AI in a single heat may improve the conception rate in repeat breeding cows. Moreover, intra-uterine infusion of antibiotic may be beneficial for treatment of repeat breeding cows with subclinical uterine infection. Accordingly, intra uterine infusion of penicillin improved the recovery rate in repeat breeding cows with uterine infection (Khair, 2005). Moreover, AI using double doses of semen has been practiced for improvement of conception in repeat breeding cows elsewhere (Islam, 2011). However, so far we know, very few studies have been conducted to determine the outcome of treatment of repeat breeding cows in Bangladesh under field conditions (Khair, 2005; Islam, 2011). Therefore, it is essential to determine the prevalence and associate risk factors for occurrence of repeat breeding in cows and also to evaluate the efficacy of the drugs or interventions used for treatment of repeat breeder cows in Bangladesh.

\section{MATERIALS AND METHODS}

\section{Location and duration of research}

The research work was conducted at the Department of Surgery and Obstetrics, Bangladesh Agricultural University, Mymensingh during the period from January 2014 to December 2014. The data were collected by interviewing the owner of the cows from 172 farms having 1524 breedable cows located at Mymensingh, Chittagong, Khulna, Satkhira, Bogra and Dhaka districts.

\section{Management of cows}

Most cattle were fed with paddy straw and green grass collected from various places. Approximately 5-10 kg roughages were given to each animal daily. Some cattle were grazed everyday for several hours in the open field and road sides. Some cattle feed were also supplemented with 500-1000 gram concentrate daily. The concentrates were mainly rice polish, wheat bran, oil-cake and common salt. All cattle had free access to drinking water. All cows were milked by hand milking keeping calves at feet of mother. The cows were milked once or twice daily. The amount of daily milk yield per cow was determined by interviewing the farmers. The daily milk yield ranged from 1 to $13 \mathrm{~L}$.

\section{Determination of age, parity and body condition score (BCS)}

The age of most cows was determined from the register book or by interviewing the owner of the cows. The parity of cows was determined by interviewing the owner of the cows. Parity of cows ranged from 1 to 9 . The scoring method of body condition involved a manual assessment of the thickness of fat covered and prominence of bone at the tail head and loin area. The tail head was scored by feeling for the amount of fat around the tail head and the prominence of the pelvic bones. The loin was scored by feeling the horizontal and vertical projections of the vertebrae and the amount of fat in-between. The BCS ranged from 2 to 3.5. On a scale of 1-5 with 0.5 fractions, a score of 1 was extremely thin and a score of 5 was extremely fat. 


\section{Evaluation of soundness of genital tract of cows}

To evaluate the breeding soundness, all repeat breeding cows were examined by per rectal palpation of genital tract following standard method. Cows with any abnormalities of the reproductive organs detectable by rectal examination or having any abnormal genital discharge were not included in the study.

\section{Determination of estrus and artificial insemination}

The farmers detected the estrus of cows on the basis of clinical manifestation of estrous signs. All cows were inseminated by trained AI technician using frozen semen. Before or during insemination, all cows were treated or received an intervention on the basis of experimental design.

\section{Determination of estrus and pregnancy after AI}

All inseminated cows were checked by the investigator for presence or absence of estrous signs at 20-22 days post-AI to determine the efficacy of the treatment or intervention. The cows which were determined non-returned to estrus at 20-22 days post-AI were examined for pregnancy diagnosis by the investigator by per rectal palpation of genital tract at 60 to 90 days post-AI. The treatment or intervention was regarded as effective if the cow conceived after receiving any treatment or intervention before or during insemination.

\section{Selection of repeat breeding cows}

The cows with the complaint of repeated conception failure were identified in the farms and the owners were interviewed for history of the problem and the cows were examined clinically for diagnosis of repeat breeding. A cow was regarded as a repeat breeder when it failed to conceive after three or more services, had normal estrus cycle, was free from palpable abnormalities, showed no abnormal vaginal discharges, delivered at least once before and had less than ten years old. A total of 122 repeat breeding cows were treated and randomly distributed into 5 experimental groups for different treatment regimes.

\section{Study design}

In experiment 1, Prevalence of repeat breeding was determined. To determine the prevalence of repeat breeding in cows, data were collected by using questionnaire from 172 farms having 1524 breedable cows located at Mymensingh (57 farms having 134 cows), Chittagong (60 farms having 472 cows), Khulna (44 farms having 261 cows), Satkhira (8 farms having 47 cows), Bogra (2 farms having 80 cows) and Dhaka (1 farm having 530 cows) districts. In experiment 2, prevalence of repeat breeding in cows with respect to breed was determined. The cows were devided into 3 groups on the basis of phenotype such as Indigenous local, Sahiwal cross and Friesian Cross, and occurrence of repeat breeding was compared among 3 breeds. In experiment 3, the effect of BCS of the herd on occurrence of repeat breeding was determined. The BCS of cows was divided into 3 groups such as 1-2, 2.5 and 3-3.5 and occurrence of repeat breeding was compared among 3 groups. In experiment 4, occurrence of repeat breeding in cows with respect to farm size was determined. The farms were divided into 3 groups such as having 1-5, 6-10 and 11-530 breedable cows and occurrence of repeat breeding was compared among 3 groups of farms. In experiment 5, the effect of age on occurrence of repeat breeding in cows was determined. The cows were divided into 3 groups such as 3-4, 5-6 and 7-13 years of age and occurrence of repeat breeding was compared among 3 age groups. In experiment 6 , the effect of parity of was determined. The parity of cows was divided into 3 groups such as $1^{\text {st }}$ parity, $2^{\text {nd }}$ to $3^{\text {rd }}$ parity and $4^{\text {th }}$ to $9^{\text {th }}$ parity, and the conception rate was compared among 3 groups of parity. In experiment 7, the effect of BCS of individual cows on occurrence of repeat breeding was determined. The BCS of cows was divided into 3 groups such as 1-2, 2.5 and 3-3.5 and occurrence of repeat breeding was compared among 3 BCS groups. In experiment 8, the effect of milk yield on occurrence of repeat breeding was determined. The milk yield of cows was divided into 3 groups such as 1-2, 2-5 and 5-13 liter daily and occurrence of repeat breeding was compared among 3 milk yield groups. In experiment 9, the efficacy of different drugs and interventions for management or treatment of repeat breeding cows was determined. The repeat breeding cows were randomly allocated into 5 treatment / intervention groups. In group $\mathrm{A}$, the cows $(\mathrm{n}=27)$ were treated with $\mathrm{i} / \mathrm{m}$ injection of $500 \mu \mathrm{g}$ Gonadorelin (an analogue of $\mathrm{GnRH}$, Fertagyl ${ }^{\circledR}$, Intervet International, The Netherlands) immediately after artificial insemination. In group B, the cows $(n=24)$ were treated with intra uterine infusion of 2.0 million penicillin (Pronapen ${ }^{\circledR}$, Renata Bangladesh Ltd.) daily for 3 days followed by single $\mathrm{Al}$ at next oestrus. In group $\mathrm{C}$, the cows $(\mathrm{n}=23)$ were inseminated with double doses of semen. In group $\mathrm{D}$, the cows $(n=25)$ were inseminated two times at 8 hours interval. In group $\mathrm{E}$, the cows $(n=23)$ were used as control and inseminated without giving any treatment or applying any intervention. 


\section{K.M. Asaduzzaman and others}

\section{Analysis of data}

The collected data were entered into the Microsoft Excel 2007 and descriptive statistics were performed. All data were analyzed by $\mathrm{T}$ test and Duncan's Multiple Range Test (DMRT) using MSTAT software. The difference between groups was considered significant when the P value was less than 0.05 .

\section{RESULTS AND DISCUSSION}

The prevalence of repeat breeding in cows with respect to different areas is presented in Table 1 . The overall prevalence of repeat breeding in cows was $11.5 \%$ and numerically the lowest occurrence was observed in Dhaka District (10.2\%) and the highest occurrence was observed in Khulna District (13.0\%). However, only one big dairy farm was examined in Dhaka district. Moreover, the prevalence of repeat breeding in cows was almost similar in different small holding dairy farms in the present study. In Sweden, the prevalence of repeat breeding in dairy heifers was $10 \%$ (Bage et al., 2002). Similar to present study, the reported prevalence of repeat breeding in cows in Bangladesh was 11\% (Boettcher and Perera, 2007).

Table 1. Prevalence of repeat breeding in cows with respect to different areas

\begin{tabular}{lccc}
\hline \multicolumn{1}{c}{ Area } & Total breedable cows & No. of repeat breeding cows & Prevalence of repeat breeding (\%) \\
\hline Mymensingh $(\mathrm{n}=57)$ & 134 & 16 & 11.9 \\
Chittagong (n=60) & 472 & 56 & 11.9 \\
Khulna (n=44) & 261 & 34 & 13.0 \\
Satkhira (n=8) & 47 & 6 & 12.8 \\
Bogra (n=2) & 80 & 9 & 11.3 \\
Dhaka (n=1) & 530 & 54 & 10.2 \\
Total & 1524 & 175 & 11.5 \\
\hline
\end{tabular}

$\mathrm{n}=$ number of farms; data were not statistically analyzed.

The prevalence of repeat breeding in cows with respect to breed is presented in Table 2 . The lowest occurrence of repeat breeding was observed in local cows $(9.5 \%)$ and the highest occurrence was observed in Friesian cross cows (11.7\%). The difference in occurrence of repeat breeding was statistically significant between two breeds $(\mathrm{P}<0.05)$. Higher prevalence of repeat breeding has also been reported in cross breed cows than those of local breed counterpart (Mandefro and Negash, 2014). The reasons for lower occurrence of repeat breeding in local cows can be explained by the fact that local cows are more tolerant to prevailing environment of Bangladesh than that by Friesian cross cows.

Table 2. Prevalence of repeat breeding in cows with respect to breed

\begin{tabular}{lccc}
\hline \multicolumn{1}{c}{ Breed } & Total breedable cows in farms & No. of repeat breeding cows & Prevalence of repeat breeding (\%) \\
\hline Local & 95 & 9 & $9.5^{\mathrm{b}}$ \\
Sahiwal cross & 164 & 18 & $10.9^{\mathrm{ab}}$ \\
Friesian cross & 1265 & 148 & $11.7^{\mathrm{a}}$ \\
\hline $\mathrm{a}, \mathrm{b}$ & Values with different superscripts within same column differed significantly from each other $(\mathrm{P}<0.05)$.
\end{tabular}

$\overline{\mathrm{a}, \mathrm{b}}$ Values with different superscripts within same column differed significantly from each other $(\mathrm{P}<0.05)$.

The prevalence of repeat breeding in cows with respect to BCS of herd is presented in Table 3 . The occurrence of repeat breeding was lower in herds with BCS $3(9.0 \%)$ and the occurrence was higher in herds with BCS 1-2 (13.9\%). The difference was statistically significant $(\mathrm{P}<0.05)$. It is likely that the cows of herds with low BCS suffer more from negative energy balance resulting in inadequate secretion of reproductive hormones causing fertilization failure or early embryonic death followed by repeat breeding. Accordingly, poor BCS caused low conception rate in cows in Bangladesh (Shamsuddin et al., 2001). Therefore, farmers should be advised to keep at least 2.5 herd BCS by providing adequate balance diet for reducing the occurrence of repeat breeding. 
Prevalence of repeat breeding and its effective treatment in cows

Table 3. Prevalence of repeat breeding in cows with respect to BCS of herd

\begin{tabular}{cccc}
\hline BCS of herd & Total breedable cows in farms & No. of repeat breeding cows & Prevalence of repeat breeding (\%) \\
\hline $1-2$ & 460 & 64 & $13.9^{\mathrm{a}}$ \\
2.5 & 630 & 72 & $11.4^{\mathrm{b}}$ \\
$3-3.5$ & 434 & 39 & $9.0^{\mathrm{c}}$ \\
\hline a,b,c Values with different superscripts within same column differed significantly from each other $(\mathrm{P}<0.05)$.
\end{tabular}

The prevalence of repeat breeding in cows with respect to farm size is presented in Table 4. The occurrence of repeat breeding was significantly lower in farms having 1-5 cows (9.6\%) than that of farms having more than 6 cows $(11-12 \%)(\mathrm{P}<0.05)$. This may be explained by the fact that cows in small farm received more individual attention from the owner than large farm (Hewett, 1968). Moreover, farms having less number of breedable cows had better heat detection than that of farms having more breedable cows. Further, it is likely that farms with low number of breedable cows had low sub-clinical uterine infection than that of farms with more breedable cows resulting in lower repeat breeding.

Table 4. Prevalence of repeat breeding in cows with respect to farm size

\begin{tabular}{cccc}
\hline Farm size & Total breedable cows & No. of repeat breeding cows & Prevalence of repeat breeding (\%) \\
\hline $1-5(\mathrm{n}=57)$ & 228 & 22 & $9.6^{\mathrm{b}}$ \\
$6-10(\mathrm{n}=53)$ & 424 & 47 & $11.1^{\mathrm{a}}$ \\
$11-530(\mathrm{n}=62)$ & 872 & 106 & $12.2^{\mathrm{a}}$ \\
\hline $\mathrm{a}, \mathrm{b}$ & & 106 &
\end{tabular}

$\overline{a, b}$ Values with different superscripts within same column differed significantly from each other $(\mathrm{P}<0.05)$.

Effects of age of cows on occurrence of repeat breeding are presented in Table 5. Among the affected cows, significantly lower proportion of cows (29.7 - 33.1\%) was affected with repeat breeding at 3-6 years of age than that of $7-13$ years of age $(37.1 \%)(\mathrm{P}<0.05)$. It has been widely documented that age impacts negatively on fertility (Hodel et al., 1995) and higher repeat breeding rates have been reported in older cows (Hewett, 1968). This may be due to variations in hypothalamic or pituitary hormonal levels or different ability of the ovarian response between different age groups (Bullman and Lamming, 1978).

Table 5. Effects of age on occurrence of repeat breeding in cows

\begin{tabular}{ccc}
\hline Age (Years) & No. of repeat breeding cows & Percentage of affected cows (\%) \\
\hline $3-4$ & 52 & $29.7^{\mathrm{b}}$ \\
$5-6$ & 58 & $33.1^{\mathrm{b}}$ \\
$7-13$ & 65 & $37.1^{\mathrm{a}}$ \\
\hline
\end{tabular}

${ }^{\mathrm{a}, \mathrm{b}}$ Values with different superscripts within same column differed significantly from each other $(\mathrm{P}<0.05)$.

Effects of parity of cows on occurrence of repeat breeding are presented in Table 6. Among the affected cows, significantly lower proportion of cows $(29.1 \%)$ was affected with repeat breeding at $2^{\text {nd }}-3^{\text {rd }}$ parity than that of cows at $1^{\text {st }}$ parity $(33.1 \%)$ and $4^{\text {th }}-9^{\text {th }}(47.7 \%)(\mathrm{P}<0.05)$. Coleman et al. $(1985)$ reported a higher conception rate in multiparous cows than that in primiparous cows. Moreover, Boyd and Reed (1961) reported an increased conception rate with advancing parity from parity 2 up to 6 , and then declined at parities 7 and 8 . This may be explained by the fact that cows with first parity may suffer from more negative energy balance than that of other parities resulting in high occurrence of repeat breeding. Because, first parity cows need more energy supplementation for milk production and its growth, and usually, the farmers supply equal quantity of feed supplement to all parous cows. 


\section{K.M. Asaduzzaman and others}

Table 6. Effects of parity on occurrence of repeat breeding in cows

\begin{tabular}{|c|c|c|}
\hline Parity & No. of repeat breeding cows & Percentage of affected cows (\%) \\
\hline $1^{\mathrm{st}}$ & 58 & $33.1^{b}$ \\
\hline $2^{\text {nd }}-3^{\text {rd }}$ & 51 & $29.1^{\mathrm{C}}$ \\
\hline $4^{\text {th }}-9^{\text {th }}$ & 66 & $47.7^{\mathrm{a}}$ \\
\hline
\end{tabular}

$\overline{a, b, c}$ Values with different superscripts within same column differed significantly from each other $(\mathrm{P}<0.05)$.

Effects of BCS of cows on occurrence of repeat breeding are presented in Table 7. Among the affected cows, significantly lower proportion of cows (26.3 - 31.4\%) suffered from repeat breeding at BCS 2.5 -3.5 than that of cows at BCS 1-2 (42.3\%) $(\mathrm{P}<0.05)$. Similar to herd BCS, individual cows with low BCS suffer more from negative energy balance resulting in increased occurrence of repeat breeding. Accordingly, negative effect of poor BCS on conception rate in cows has been documented elsewhere (Shamsuddin et al., 2001).

Table 7. Effects of BCS on occurrence of repeat breeding in cows

\begin{tabular}{ccc}
\hline BCS of cows & No. of repeat breeding cows & Percentage of affected cows (\%) \\
$1-2$ & 74 & $42.3^{\mathrm{a}}$ \\
2.5 & 55 & $31.4^{\mathrm{b}}$ \\
$3-3.5$ & 46 & $26.3^{\mathrm{b}}$ \\
\hline a,b, & 4 alues with different superscripts within same column differed significantly from each other $(\mathrm{P}<0.05)$.
\end{tabular}

$\overline{\mathrm{a}, \mathrm{b},}$ Values with different superscripts within same column differed significantly from each other $(\mathrm{P}<0.05)$.

Effects of milk yield of cows on occurrence of repeat breeding are presented in Table 8. Among the affected cows, significantly lower proportion of cows (21.1\%) were affected when they produced 1-2 litres of milk than that of $>2-13$ litres of milk $(26.3-52.6 \%)(\mathrm{P}<0.05)$. An increase of daily milk yield of approximately $15 \mathrm{~kg}$ might increase 1.5 times risk of repeat breeding (Gustafsson and Emanuelson, 2002). Contrasting to the present findings, Shamsuddin et al. (2001) reported that conception rate increased in cows with increasing milk yield in Bangladesh which indirectly indicated the lower occurrence of repeat breeding in high yielding cows. In the present study, most low yielding cows were of local breed and breedable cows in each farm were also low which resulted in lower occurrence of repeat breeding. Moreover, most high yielding cows in the present study were of Friesian cross and number of breedable cows in each farm was also high which resulted in more occurrence of repeat breeding.

Table 8. Effects of milk yield on occurrence of repeat breeding in cows

\begin{tabular}{ccc}
\hline Milk Yield (Litres) & No. of repeat breeding cows & Percentage of affected cows (\%) \\
\hline $1-2$ & 37 & $21.1^{\mathrm{c}}$ \\
$>2-5$ & 46 & $26.3^{\mathrm{b}}$ \\
$>5-13$ & 92 & $52.6^{\mathrm{a}}$ \\
\hline
\end{tabular}

$\overline{\mathrm{a}, \mathrm{b}, \mathrm{c}}$ Values with different superscripts within same column differed significantly from each other $(\mathrm{P}<0.05)$.

The efficacy of different regimens used for treatment of repeat breeding in cows is presented in Table 9 . The significantly higher proportion of cows recovered when AI was done using double doses of semen (52.8\%), single AI with GnRH injection (51.9\%), two times AI at 8 hours interval (48.0\%) or intrauterine administration of antibiotics followed by $\mathrm{AI}$ in next heat $(45.8 \%)$ than that of no treatment control group (30.4\%) $(\mathrm{P}<0.05)$. 
Prevalence of repeat breeding and its effective treatment in cows

Table 9. The efficacy of different regimens used for treatment of repeat breeding in cows

\begin{tabular}{lccc}
\hline \multicolumn{1}{c}{ Treatment regime } & $\begin{array}{c}\text { No. of cows } \\
\text { treated }\end{array}$ & $\begin{array}{c}\text { No. of cows } \\
\text { conceived }\end{array}$ & Recovery (\%) \\
\hline Single AI with injection of 500 $\mu$ g of gonadorelin & 27 & 14 & $51.9^{\mathrm{ab}}$ \\
I/U infusion of 4.0 million i.u. penicillin daily for 3 days & 24 & 11 & $45.8^{\mathrm{c}}$ \\
followed by single AI at next oestrus & 23 & 12 & $52.8^{\mathrm{a}}$ \\
Same time AI with double doses of semen & 25 & 12 & $48.0^{\mathrm{bc}}$ \\
Two times AI at 8 hours interval & 23 & 7 & $30.4^{\mathrm{d}}$ \\
Single AI without any intervention (Control) & & 7 &
\end{tabular}

a,b,c Values with different superscripts within same column differed significantly from each other $(\mathrm{P}<0.05)$.

It is likely that old cows with high number of parities may have large pendulus uterus due to repeated pregnancy related changes in uterus. These cows may show repeated conception failure since small volume of frozen semen might not be enough to fertilize in the oviduct after traveling a long distance from uterus to horn by the spermatozoa. For this reason, AI with double doses of semen might improve the recovery rate in repeat breeding cows in the present study.

The present investigation also clearly demonstrates that the repeat breeding cows can be successfully managed by treating with single dose of GnRH immediate after AI. The improvement in conception rate after GnRH treatment in the present study is in agreement with the study of Lee et al. (1983) who reported 25\% higher conception rate in $\mathrm{GnRH}$ treated cows than that in control. In the present study, a good proportion of repeat breeding cows conceived after using double times insemination at 8 hours interval which was higher than control group. This means, a satisfactory number of repeat breeding cows can be recovered without treating with any antibiotics or hormones. This may be explained by the fact that certain proportion of repeat breeding cows might be inseminated either early or late causing fertilization failure. Accordingly, it has been reported that double inseminations during the same estrous period at the time of their third or fourth service improved conception rates in cattle which was similar to injections of $\mathrm{GnRH}$ at the time of AI (Jeffrey et al., 1990).

In the present study, conception rate in the repeat breeding cows also improved after treating with intra uterine infusion of penicillin for successive three days followed by single Al at next estrus. This is in agreement with previous study of Khair (2005) who obtained higher recovery rate of repeat breeding cows after treatment with penicillin than that of their controls. This may be explained by the fact that the cows those were having 3 or more services without successful fertilization had more chance to have uterine infection than that of 1 or 2 services received counterpart. Uterine infection has long been considered as an important cause of bovine infertility elsewhere (Erb et al., 1981).

In conclusions, the overall prevalence of repeat breeding in cows is $11.5 \%$ in the selected areas of Bangladesh. Breed of cows, herd BCS and farm size may influence the prevalence of repeat breeding. Age, parity, BCS and milk yield may affect the occurrence of repeat breeding in individual cows. AI with double dose of semen and single AI with GnRH administration may improve the conception rate in repeat breeding cows.

\section{ACKNOWLEDGEMENT}

This research work has been funded by University Grants Commission (UGC) of Bangladesh.

\section{REFERENCES}

1. Alam MGS and Gosh A (1988). Reproductive performance in cows: its relation to parity and season. Bangladesh Veterinary Journal 22: 51-61.

2. Bage R, Gustaffson H, Larsson B, Forsberg M and Rodriguer-Martinez H (2002). Repeat breeding in dairy heifers: follicular dynamics and estrus cycle characteristics in relation to sexual hormone patterns. Theriogenology 57: 2257-2267.

3. Bartlett PC, Kirk JH and Mather EC (1986). Repeated insemination in Michigan Holstein-Friesian cattle: incidence, descriptive epidemiology and estimated economic impact. Theriogenology 26: 309-322. 


\section{K.M. Asaduzzaman and others}

4. Boettcher PJ and Perera BMAO (2007). Improving the reproductive management of small holder dairy cattle and the effectiveness of artificial insemination: a summary. IAEA Tecdoc 1533: 1-8.

5. Boyd H and Reed HCB (1961). Investigation into the incidence and causes of infertility in dairy cattle: I. fertility variations. British Veterinary Journal 117: 18-35.

6. Bulman DC and Lamming GE (1978). Milk progesterone levels in relation to conception, repeat breeding and factors influencing acyclity in dairy cows. Journal of Reproduction and Fertility 54: 447- 458.

7. Coleman DA, Thayne WV and Dailey RA (1985). Factors affecting reproductive performance of dairy cows. Journal of Dairy Science 68: 1793-1803.

8. Erb HN, Martin SW and Ison N (1981). Interrelationship between production and reproductive disease in Holstein cows: conditional relationship between production and disease. Journal of Dairy Science 64: 272-281.

9. Gustafsson H and Emanuelson U (2002). Characterisation of the repeat breeding syndrome in Swedish dairy cattle. Acta Veterinaria Scandinavica 43: 115-125.

10. Hewett CD (1968). A survey of the incidence of the repeat breeder cows in Sweden with reference to herd size, season, age and milk yield. British Veterinary Journal 124: 342-352.

11. Hodel F, Moll J and Kunzi N (1995). Factor affecting fertility in cattle. Schweizer Fleckvieh 4: 14-24.

12. Hossain MM (2002). Improvement of conception in repeat breeding cows using synthetic gonadotrophin releasing hormone. MS in Theriogenology Thesis. Department of Surgery and Obstetrics, Faculty of Veterinary Science, Bangladesh agricultural University, Mymensingh.

13. Islam N (2011). Efficacy studies of drugs used for the treatment of repeat breeding cows at Bangladesh Agricultural University Veterinary Clinic. MS in Theriogenology Thesis. Department of Surgery and Obstetrics, Faculty of Veterinary Science, Bangladesh Agricultural University, Mymensingh, Bangladesh.

14. Jainudeen MR and Hafez ESE (2000). Reproductive failure in females. In: Hafez ESE and Hafez B edited Reproduction in farm animals ( $7^{\text {th }}$ edition), Lippincott Williams and Wilkins, Philadelphia, pp. 261-278.

15. Jeffrey S, Stevenson and Edward P (1990). Double insemination and gonadotropin-releasing hormone treatment of repeat-breeding dairy cattle. Journal of Dairy Science 73: 1766-1772.

16. Khair A (2005). Hormonal intervention to increase the fertility in anoestrus and repeat breeding cows at Bangladesh Agricultural University veterinary clinic. MS in Theriogenology Thesis. Department of Surgery and Obstetrics, Faculty of Veterinary Science, Bangladesh agricultural University, Mymensingh, Bangladesh.

17. Lafi SO and Kaneene JB (1992). Epidemiological and economical study of the repeat breeding syndrome in Michigan dairy cattle. Preventive Veterinary Medicine 14: 87-98.

18. Lee CN, Maurice E and Ax RI (1983). Efficacy of gonadotropin-releasing hormone administered at the time of artificial insemination of heifers and post-partum repeat breeder dairy cows. American Journal of Veterinary Research 44: 2160-2163.

19. Mandefro M and Negash G (2014). Repeat breeder syndrome in dairy cows: influence of breed and age on its prevalence. World Journal of Agricultural Sciences 10: 200-203.

20. Mia AS and Islam H (1967). A preliminary investigation on the incidence of infertility in cattle and economic losses caused by them. Pakistan Journal of Veterinary Science 1: 5-9.

21. Nebel RL and Jobst SM (1998). Evaluation of systematic breeding programmes for lactating cows: a review. Journal of Dairy Science 81: 1169-1174.

22. Shamsuddin M, Bhuiyan MMU, Sikder TK, Sugulle AH, Chanda PK, Alam MGS and Galloway D (2001). Constraints limiting the efficiency of artificial insemination of cattle in Bangladesh. IAEA Tecdoc 1220: 9-27.

23. Taponen J, Katila T and Rodriguez-Martinez H (1999). Induction of ovulation with gonadotrophin releasing hormone during pro-estrous in cattle: Influence of subsequent follicular growth and luteal function. Animal Reproduction Science 55: 91-105.

24. Zemjanis R (1980). Repeat breeding or conception failure in cattle. In: Morrow DA edited, Current Therapy in Theriogenology: diagnosis, treatment and prevention of reproductive diseases in animals, $2^{\text {nd }}$ edition, WB Saunders, Philadelphia pp. 205-213. 